\title{
Assessing Tumor Hypoxia in Cervical Cancer by PET with ${ }^{60} \mathrm{Cu}$-Labeled Diacetyl-Bis $\left(N^{4}\right.$-Methylthiosemicarbazone)
}

\author{
Farrokh Dehdashti ${ }^{1,2}$, Perry W. Grigsby ${ }^{2,4}$, Jason S. Lewis ${ }^{2,3}$, Richard Laforest ${ }^{1,3}$, Barry A. Siegel ${ }^{1,2}$, and \\ Michael J. Welch ${ }^{2,3}$ \\ ${ }^{1}$ Division of Nuclear Medicine, Edward Mallinckrodt Institute of Radiology, St. Louis, Missouri; ${ }^{2}$ Siteman Cancer Center, Washington \\ University School of Medicine, St. Louis, Missouri; ${ }^{3}$ Division of Radiological Sciences, Edward Mallinckrodt Institute of Radiology, \\ St. Louis, Missouri; and ${ }^{4}$ Department of Radiation Oncology, Edward Mallinckrodt Institute of Radiology, St. Louis, Missouri
}

Tumor hypoxia indicates a poor prognosis. This study was undertaken to confirm our prior pilot results showing that pretreatment tumor hypoxia demonstrated by PET with ${ }^{60} \mathrm{Cu}$-labeled diacetylbis $\left(N^{4}\right.$-methylthiosemicarbazone) $\left({ }^{60} \mathrm{Cu}-\mathrm{ATSM}\right)$ is a biomarker of poor prognosis in patients with cervical cancer. Thirty-eight women with biopsy-proved cervical cancer underwent ${ }^{60} \mathrm{Cu}$ ATSM PET before the initiation of radiotherapy and chemotherapy. ${ }^{60} \mathrm{Cu}$-ATSM uptake was evaluated semiquantitatively as the tumor-to-muscle activity ratio (T/M). A log-rank test was used to determine the cutoff uptake value that was strongly predictive of prognosis. All patients also underwent clinical PET with ${ }^{18} \mathrm{~F}-\mathrm{FDG}$ before the institution of therapy. The PET results were correlated with clinical follow-up. Tumor ${ }^{60} \mathrm{Cu}$-ATSM uptake was inversely related to progression-free survival and cause-specific survival $(P=0.006$ and $P=0.04$, respectively, as determined by the log-rank test). We found that a T/M threshold of 3.5 best discriminated patients likely to develop a recurrence from those unlikely to develop a recurrence; the 3-y progression-free survival of patients with normoxic tumors (as defined by $\mathrm{T} / \mathrm{M}$ of $\leq 3.5$ ) was $71 \%$, and that of patients with hypoxic tumors (T/M of $>3.5$ ) was $28 \%(P=0.01)$. Tumor ${ }^{18} \mathrm{~F}-\mathrm{FDG}$ uptake did not correlate with ${ }^{60} \mathrm{Cu}$-ATSM uptake, and there was no significant difference in tumor ${ }^{18} \mathrm{~F}-\mathrm{FDG}$ uptake between patients with hypoxic tumors and those with normoxic tumors $(P=0.9)$. Pretherapy ${ }^{60} \mathrm{Cu}$-ATSM PET provides clinically relevant information about tumor oxygenation that is predictive of outcome in patients with cervical cancer.

Key Words: PET; ${ }^{60} \mathrm{Cu}-\mathrm{ATSM}$; hypoxia; cervical cancer; survival

J Nucl Med 2008; 49:201-205

DOI: 10.2967/jnumed.107.048520

\section{$\mathbf{T}$} umor hypoxia has been shown to be important in determining the response to therapy in solid tumors, including

\footnotetext{
Received Oct. 23, 2007; revision accepted Nov. 19, 2007.

For correspondence or reprints contact: Farrokh Dehdashti, MD, Edward Mallinckrodt Institute of Radiology, 510 South Kingshighway Blvd., St. Louis, MO 63110.

E-mail: dehdashtif@mir.wustl.edu

COPYRIGHT @ 2008 by the Society of Nuclear Medicine, Inc.
}

cervical cancer. Hypoxic cells are more resistant to killing by ionizing radiation and chemotherapy, more likely to be locally invasive and to metastasize, more resistant to apoptosis, and more genetically unstable $(1,2)$. Thus, because of the importance of tumor hypoxia, considerable research has focused on developing methods to measure hypoxia reliably as well as on strategies for improving tumor oxygenation or ameliorating the effects of hypoxia. Considering the new therapeutic agents that target hypoxia, identifying a practical method for detecting hypoxia becomes highly important. In general, a method suitable for routine clinical application needs to be practical, readily available, and reliable. Polarographic oxygen electrodes (Eppendorf $\mathrm{GmbH}$ ) made it possible to measure tumor oxygenation, which produced clinically relevant information. Early clinical studies with oxygen electrodes were very promising and demonstrated that hypoxic tumors, including cervical tumors, respond poorly to radiation therapy $(3-10)$. However, the oxygen electrode method is invasive, technically demanding, useful only for studying tumors accessible to electrode placement, and subject to sampling errors. Thus, this method is not considered clinically practical.

Recently, noninvasive imaging methods, particularly PET, have received substantial attention. Several hypoxic tracers suitable for PET are being evaluated. One of most promising of these is ${ }^{60} \mathrm{Cu}$-labeled diacetyl-bis $\left(N^{4}\right.$-methylthiosemicarbazone) $\left({ }^{60} \mathrm{Cu}\right.$-ATSM) $(11) .{ }^{60} \mathrm{Cu}$-ATSM has rapid blood clearance and is rapidly reduced and retained in hypoxic tissues with a high hypoxic/normoxic tissue activity ratio (12). We recently reported our preliminary results using ${ }^{60} \mathrm{Cu}-$ ATSM PET in patients with cervical cancer (13). We demonstrated that ${ }^{60} \mathrm{Cu}$-ATSM uptake was predictive of prognosis in patients with locally advanced cervical cancer. The present study was performed to confirm our initial results with a larger group of patients.

\section{MATERIALS AND METHODS \\ Patients}

We prospectively studied 38 patients (23-84 y old) who had biopsy-proved cervical cancer and who underwent PET with 
${ }^{60} \mathrm{Cu}$-ATSM before the initiation of therapy. The results for 14 of these patients included in our pilot study were reported previously (13). This investigation was approved by the Human Studies Committee and the Radioactive Drug Research Committee of Washington University School of Medicine and by the Protocol Review and Monitoring Committee of the Siteman Cancer Center at Washington University School of Medicine. All patients gave informed consent before participating in the study.

All patients were initially evaluated before treatment with a history (smoking history was not recorded), a physical examination, routine laboratory studies (all patients had hemoglobin levels measured, and these averaged $11.9 \pm 2.4$ [mean $\pm \mathrm{SD}$ ] g/dL before therapy), a cervical biopsy, chest radiography, abdominopelvic CT, and wholebody PET with ${ }^{18} \mathrm{~F}$-FDG, performed as part of our clinical routine. Therapy for the cervical cancer was done in accordance with standard treatment policies at the Edward Mallinckrodt Institute of Radiology $(14,15)$. All patients received external irradiation and intracavitary brachytherapy. Concurrent weekly cisplatin chemotherapy $\left(40 \mathrm{mg} / \mathrm{m}^{2}\right.$ weekly for 6 cycles) was given to 35 patients; the remaining 3 patient did not receive chemotherapy (because of severe comorbidity). Clinical follow-up was performed $6 \mathrm{wk}$ after the completion of radiotherapy, at 3-mo intervals for the next $2 \mathrm{y}$, and then every 6 mo thereafter. Standard criteria were used to evaluate the response to therapy $(14,15)$. The duration of follow-up for patients alive at the time of the last evaluation ranged from 3 to 79 mo. Progression-free survival and cause-specific survival were measured from the date of completion of irradiation to the date of recurrence or death.

\section{Radiopharmaceutical Synthesis}

${ }^{60} \mathrm{Cu}$ (half-life $=0.395 \mathrm{~h}, \beta$ positron decay $=92.5 \%$, electron capture $=7.5 \%$ ) was produced in the Cyclotron Corp. CS15 cyclotron at the Washington University Medical Center according to previously described procedures $(16) .{ }^{60} \mathrm{Cu}$-ATSM was produced according to previously described methods (17). In brief, ${ }^{60} \mathrm{CuCl}_{2}$ was buffered with $1 \mathrm{M}$ sodium acetate, $15 \mu \mathrm{g}$ of $\mathrm{H}_{2}$ ATSM (in dimethyl sulfoxide at $1 \mathrm{mg} / \mathrm{mL}$ ) was added, and mixing was done for $2 \mathrm{~min}$. The ${ }^{60} \mathrm{Cu}$-ATSM-containing solution was transferred to a preconditioned $\mathrm{C}_{18}$ SepPak Light cartridge (Millipore Corp.), which was washed with water, and then the final ${ }^{60} \mathrm{Cu}$-ATSM was eluted from the cartridge in $0.1-\mathrm{mL}$ fractions of ethanol. The fractions containing the peak amounts of activity were combined, and the ethanol fraction was diluted with sodium chloride for injection. The final sterile, apyrogenic, and isotonic ${ }^{60} \mathrm{Cu}$-ATSM solution had greater than $98 \%$ radiochemical purity at the time of injection.

\section{PET}

PET with ${ }^{60} \mathrm{Cu}$-ATSM was performed with an ECAT HR+ scanner (Siemens-CTI). The performance specifications of this scanner were previously reported (18); the scanner has a spatial resolution of $4.5 \mathrm{~mm}$ full width at half maximum (FWHM).

The imaging level was determined by centering the tumor in the scanner field of view by use of positioning lasers and by reference to anatomic landmarks (e.g., pubic symphysis) seen on the CT study or the clinical ${ }^{18}$ F-FDG PET study. After the completion of a 10- to 15-min transmission scan, approximately $481 \mathrm{MBq}$ of ${ }^{60} \mathrm{Cu}$-ATSM were injected intravenously. All patients then underwent a 60-min dynamic study $(30 \times 3$-s frames, $12 \times 10$-s frames, $6 \times 20$-s frames, $5 \times$ 1 -min frames, and $10 \times 5$-min frames). ${ }^{60} \mathrm{Cu}$-ATSM PET images were reconstructed by filtered backprojection with measured attenuation factors from the transmission scans. A postreconstruction gaussian filter of $5 \mathrm{~mm}$ FWHM was used, corresponding to a final spatial resolution of approximately $8 \mathrm{~mm}$ FWHM, neglecting the loss of resolution attributable to the positron range for ${ }^{60} \mathrm{Cu}$.

\section{Image Analysis}

For qualitative analysis, the ${ }^{60} \mathrm{Cu}$-ATSM PET images were first evaluated subjectively by an experienced nuclear medicine physician. The images were then evaluated in correlation with the CT and ${ }^{18} \mathrm{~F}$ FDG PET images. In addition, overall tumor ${ }^{60} \mathrm{Cu}$-ATSM uptake was assessed semiquantitatively by determining the tumor-to-muscle activity ratio (T/M) from the summed images obtained at 30-60 min after injection. This time interval was based on our previous studies of patients with non-small cell lung cancer (NSCLC) and cervical cancer; those studies demonstrated that semiquantitative analysis of the summed data obtained at 30-60 min after injection provides information similar to that achieved with a more formal quantitative analysis of the images $(13,19)$. In addition, this time interval represented a practical trade-off between image contrast and image noise, considering the short half-life of ${ }^{60} \mathrm{Cu}$-ATSM.

Clinical ${ }^{18}$ F-FDG PET images were evaluated qualitatively with image interpretation criteria routinely used for scintigraphic imaging. In addition, ${ }^{18} \mathrm{~F}$-FDG uptake in the primary tumor was assessed semiquantitatively by determination of the maximum standardized uptake value $\left(\mathrm{SUV}_{\max }\right)$ in the primary tumor.

\section{Statistical Analysis}

To assess whether the tumor uptake of either ${ }^{60} \mathrm{Cu}$-ATSM or ${ }^{18} \mathrm{~F}$ FDG is predictive of the response to treatment, the PET results were correlated with the results of clinical follow-up. The physician who assessed the patients for disease progression was unaware of the results of the ${ }^{60} \mathrm{Cu}$-ATSM studies. The Kaplan-Meier method was used to assess the relationship between ${ }^{60} \mathrm{Cu}$-ATSM uptake and both progression-free and cause-specific survival rates. The equivalence of survival curves was tested with log-rank (Mantel-Cox) statistics. A log-rank test was used to determine the cutoff uptake value that was strongly predictive of prognosis. The relationships between ${ }^{60} \mathrm{Cu}-$ ATSM uptake in the primary tumor and the presence of metastatic involvement of the pelvic lymph nodes (as assessed by ${ }^{18} \mathrm{~F}$-FDG PET) and stage of disease were assessed by use of the Fisher exact and $\chi^{2}$ statistics, respectively. The correlation between the tumor uptake of ${ }^{60} \mathrm{Cu}$-ATSM and that of ${ }^{18} \mathrm{~F}$-FDG was evaluated by linear regression.

\section{RESULTS}

All patients had locally advanced cervical cancer with primary lesions of $>2.0 \mathrm{~cm}$ in diameter (International Federation of Gynecology and Obstetrics clinical stage Ib1 in 3 patients, stage Ib2 in 3 patients, stage IIa in 1 patient, stage IIb in 18 patients, IIa in 1 patient, IIIb in 11 patients, and IVa in 1 patient). Histologic analysis revealed the tumors to be squamous cell carcinomas in 37 patients and an adenosquamous carcinoma in 1 patient.

All patients underwent clinical ${ }^{18} \mathrm{~F}-\mathrm{FDG}$ PET. These studies demonstrated markedly increased ${ }^{18} \mathrm{~F}-\mathrm{FDG}$ uptake in the primary cervical tumors of all patients. The SUV $\max$ for the primary tumors was $11.5 \pm 6.7$ (mean $\pm \mathrm{SD}$ ). The uptake of ${ }^{60} \mathrm{Cu}$-ATSM in the cervical cancers was variable. The tumor of one patient had no discernible ${ }^{60} \mathrm{Cu}$-ATSM uptake. The tumors of the remaining 37 patients had measurable uptake of ${ }^{60} \mathrm{Cu}$-ATSM. The T/M of ${ }^{60} \mathrm{Cu}$-ATSM in all patients was $3.8 \pm 2.0$ (mean $\pm \mathrm{SD}$ ). 
The patients were monitored for periods ranging from 3 to 79 mo (median $=38.5 \mathrm{mo}$ ). At the last follow-up, 27 patients were alive for periods ranging from 3 to 84 mo (median $=$ $41 \mathrm{mo}$ ), 24 with no evidence of cervical cancer and 3 with a recurrence of cervical cancer. The remaining 11 patients had died, 10 from recurrent cervical cancer and 1 from intercurrent disease). Using log-rank analysis of our previously reported data, we found that a T/M threshold of 3.5 was a statistically significant cutoff value that accurately distinguished patients whose cancer did not recur from those who developed a recurrence after completing therapy. In the present study, this cutoff value appeared to have similar discriminatory power. The Kaplan-Meier survival estimates for patients with T/M values above and below 3.5 are shown in Figure 1. Progression-free survival and cause-specific survival were significantly better in patients with a T/M for ${ }^{60} \mathrm{Cu}$-ATSM of $\leq 3.5$ ( $P=0.006$ and $P=0.04$, respectively). The 3-y progression-free survival of patients with normoxic tumors (T/M of $\leq 3.5)$ was $71 \%$, and that of patients with hypoxic tumors (T/M of $>3.5)$ was $28 \%(P=$ $0.01)$. The corresponding cause-specific survival estimates were $74 \%$ and $49 \%$, respectively $(P=0.05)$. There was no significant difference in the frequency of lymph node involvement between patients with a T/M of $>3.5(9 / 16$; $56 \%)$ and patients with a T/M of $\leq 3.5(9 / 22 ; 41 \%)(P=$ 0.6). Also, there was no significant correlation between disease stage and tumor ${ }^{60} \mathrm{Cu}$-ATSM uptake $(P=0.46)$. There was no significant difference in total radiation dose $(P=0.22)$ or overall treatment time $(P=0.98)$ between patients with a T/M of $>3.5$ and patients with a T/M of $\leq 3.5$. Figures 2 and 3 show examples of hypoxic and normoxic tumors.

There was no significant correlation between the tumor SUV $_{\text {max }}$ for ${ }^{18} \mathrm{~F}$-FDG and the tumor uptake of ${ }^{60} \mathrm{Cu}$-ATSM $\left(R^{2}=0.006, P=0.63\right)$. The tumor uptake of ${ }^{18} \mathrm{~F}-\mathrm{FDG}$ in hypoxic tumors was $11.7 \pm 4.2$ (mean $\pm \mathrm{SD}$ ), and that in normoxic tumors was $11.5 \pm 8.4(P=0.9$, as determined by an unpaired $t$ test).

\section{DISCUSSION}

Hypoxia has been known to be a characteristic feature of solid tumors and to play a crucial role in determining the response to therapy and tumor progression (l). Therefore,
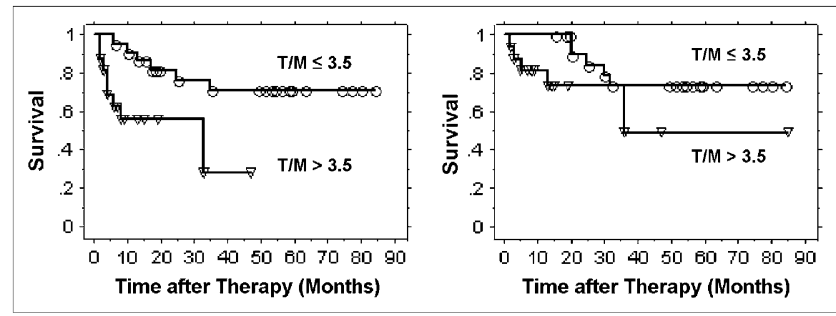

FIGURE 1. Progression-free survival (left) and cause-specific survival (right) determined from ${ }^{60} \mathrm{Cu}$-ATSM uptake by KaplanMeier method. $\bigcirc=$ event in patients with $\mathrm{T} / \mathrm{M}$ of $\leq 3.5 ; \nabla=$ event in patients with $\mathrm{T} / \mathrm{M}$ of $>3.5$.

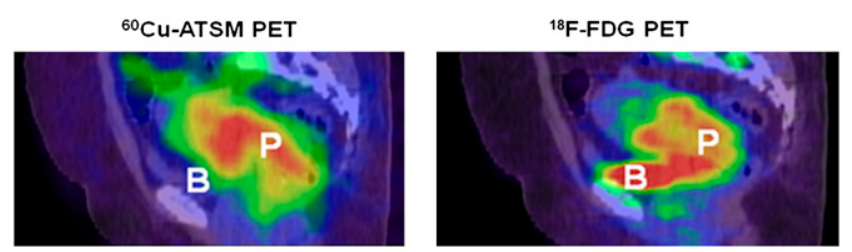

FIGURE 2. Hypoxic tumor. Sagittal ${ }^{18}$ F-FDG PET/CT image (right) of pelvis shows intense ${ }^{18} \mathrm{~F}-\mathrm{FDG}$ uptake in known primary cervical cancer. Sagittal ${ }^{60} \mathrm{Cu}$-ATSM PET image coregistered with CT image (left) at same level also demonstrates intense uptake in primary cervical cancer $(\mathrm{T} / \mathrm{M}=4.5)$. Note that there are different patterns of ${ }^{18} \mathrm{~F}-\mathrm{FDG}$ uptake and ${ }^{60} \mathrm{Cu}$-ATSM uptake in primary tumor $(\mathrm{P}) . \mathrm{B}=$ urinary bladder.

several therapeutic strategies have been developed to overcome hypoxia or its effects, either by eliminating the hypoxic state (e.g., blood transfusions or hyperbaric oxygenation) or by sensitizing hypoxic cells to radiation with hypoxic cell sensitizers (e.g., misonidazole). For these treatments to be successful, the ability to identify hypoxia before therapy and to monitor hypoxia during therapy with a clinically practical method would be quite important. Such a method could serve as a tool to improve and optimize patient care.

Direct measurement of tumor oxygenation was not possible until the introduction of polarographic oxygen electrodes in the 1980s. Clinical data obtained with oxygen electrodes demonstrated the clinical relevance of tumor hypoxia ( 7 , $20,21)$. These clinical studies demonstrated that tumor oxygenation is predictive of the response to therapy and the treatment outcome (21-24). However, this method is invasive, difficult to use, and unable to address tumor heterogeneity, which is an important feature of solid tumors; thus, this method is not considered to be practical for routine clinical use. Imaging, as a noninvasive method, has attracted much attention. Imaging with hypoxic markers has the ability to evaluate the entire tumor and thus is less prone to sampling errors. Additionally, imaging allows for serial assessment of the tumor during therapy and can demonstrate the effects of therapy on the hypoxic regions of the tumor. Among the different types of imaging, PET with various hypoxic radiotracers has garnered the most attention.

${ }^{18}$ F-Fluoromisonidazole (3-fluoro-1-(2'-nitro-1'-imidazolyl)2-propanol; FMISO) is the most widely studied agent for which uptake is dependent on tissue oxygen levels and that
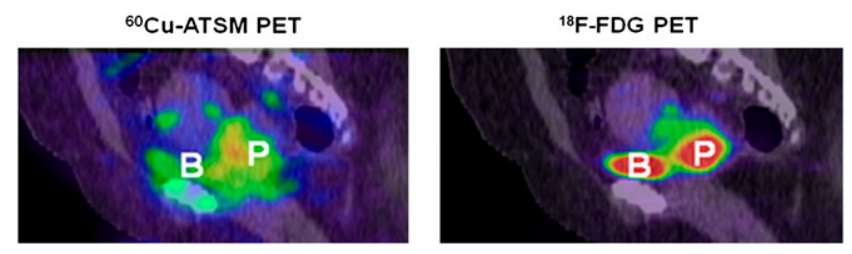

FIGURE 3. Normoxic tumor. Sagittal ${ }^{18} \mathrm{~F}-\mathrm{FDG}$ PET/CT image (right) of pelvis shows intense ${ }^{18} \mathrm{~F}-\mathrm{FDG}$ uptake in known primary cervical cancer. Sagittal ${ }^{60} \mathrm{Cu}$-ATSM PET image coregistered with CT image (left) at same level demonstrates only mildly increased uptake of this tracer in primary cervical cancer $(T / M=3.0)$. As in Figure 2, there are different patterns of ${ }^{18} \mathrm{~F}-\mathrm{FDG}$ uptake and ${ }^{60} \mathrm{Cu}-$ ATSM uptake in primary tumor $(\mathrm{P})$. B = urinary bladder. 
has been used for hypoxia imaging in cancer patients. FMISO accumulates in oxygen-deprived viable cells (25). The first clinical studies to image hypoxia by PET were done with FMISO. Padhani et al. reported changes in FMISO uptake with therapy (25). Eschmann et al. demonstrated that high FMISO uptake at $4 \mathrm{~h}$ after injection was highly associated with an incomplete response to curative radiotherapy in patients with head and neck cancers or NSCLC (26). For patients with head and neck cancers, Rischin et al. showed that the risk of local recurrence was significantly higher in patients with hypoxic tumors (27). However, the pharmacokinetics of FMISO, which result in only modest target-to-background ratios, have limited its routine clinical use. In addition, urinary excretion of this tracer interferes with the imaging of pelvic organs located near the urinary bladder.

However, ${ }^{60} \mathrm{Cu}$-ATSM, a more recently developed PET tracer, holds exceptional promise for the imaging of hypoxic regions in tumors. The mechanism of retention of ${ }^{60} \mathrm{Cu}$-ATSM in hypoxic tissues is largely attributed to low oxygen tension and the subsequent altered redox environment (increased nicotinamide adenine dinucleotide levels) (11). Several in vivo and in vitro animal studies have shown that ${ }^{60} \mathrm{Cu}$-ATSM accumulates selectively in hypoxic cells, clears rapidly from the blood, and washes out rapidly from normoxic cells (11). One of the important properties of this tracer is its minimal excretion by the urinary tract, which makes it ideal for the evaluation of pelvic organs. In small prospective clinical studies, we found that pretreatment tumor ${ }^{60} \mathrm{Cu}$-ATSM uptake was predictive of the response in NSCLC and was predictive of both the response to neoadjuvant chemoradiotherapy and survival in patients with rectal cancer $(19,28)$. We previously reported, for 14 patients with cervical cancer, that ${ }^{60} \mathrm{Cu}$-ATSM uptake was predictive of prognosis (13). We now report our expanded experience for 38 patients with cervical cancer. We confirmed the results of our earlier report and found that tumor ${ }^{60} \mathrm{Cu}$-ATSM uptake, as measured by T/M, allows for the reliable discrimination of patients with a high likelihood of early relapse from those with a low likelihood of early relapse. As in our earlier report, we found that the T/M cutoff value of 3.5 was reliable for predicting progressionfree and cause-specific survival in this group of patients. Patients with hypoxic tumors (T/M of $>3.5$ ) had significantly shorter progression-free and cause-specific survival times than did those with normoxic tumors ( $\mathrm{T} / \mathrm{M}$ of $\leq 3.5$ ) $(P=0.006$ and $P=0.04$, respectively).

${ }^{18}$ F-FDG PET has been successfully used for the imaging of oncology patients. The magnitude of ${ }^{18} \mathrm{~F}-\mathrm{FDG}$ uptake has been shown to be an important prognostic factor independent of established prognostic factors in patients with tumors such as lung cancer and breast cancer $(29,30)$. Preclinical studies of human tumor cell lines and clinical data suggest that hypoxia plays a role in tumor ${ }^{18} \mathrm{~F}-\mathrm{FDG}$ uptake (31-35). It has been shown that hypoxia increases the level of hypoxia-inducible factor $1 \alpha$, which increases the expression of glycolytic enzymes and glucose transport proteins (36). However, many other factors affect ${ }^{18} \mathrm{~F}-\mathrm{FDG}$ uptake in tumors; thus, ${ }^{18} \mathrm{~F}$-FDG is not a specific marker of hypoxia. Double-tracer autoradiography with ${ }^{64} \mathrm{Cu}$-ATSM and ${ }^{18} \mathrm{~F}-\mathrm{FDG}$ and immunohistochemical staining of proliferating cells (Ki67), blood vessels (CD34 or von Willebrand factor), and apoptotic cells in 4 different implanted tumor models in mice demonstrated that regions with high ${ }^{64} \mathrm{Cu}$-ATSM uptake were hypovascular and consisted of tumor cells arrested in the cell cycle, whereas regions with high ${ }^{18} \mathrm{~F}-\mathrm{FDG}$ uptake were hypervascular and consisted of proliferating cells (37). Rajendran et al. studied patients with head and neck cancers, soft-tissue sarcoma, breast cancer, or glioblastoma multiforme and found that the correlation between the overall tumor ${ }^{18} \mathrm{~F}$-FDG uptake and the hypoxic volume (as measured with FMISO) was small (Spearman $r=0.24$ ), with highly significant differences among the different tumor types (35). Thus, ${ }^{18} \mathrm{~F}-\mathrm{FDG}$ uptake, which might indicate the presence of hypoxia, should not be considered a surrogate marker for hypoxia. Although hypoxic tracers map the hypoxic regions of tumors, several studies have compared the uptake of ${ }^{18} \mathrm{~F}$ FDG and FMISO or ${ }^{60} \mathrm{Cu}$-ATSM and have demonstrated that these tracers provide different types of information about tumors $(38,39)$. We found no significant correlation between ${ }^{60} \mathrm{Cu}$-ATSM and ${ }^{18} \mathrm{~F}$-FDG in patients with cervical cancer, a finding similar to our findings for patients with rectal cancer and NSCLC $(19,28)$. No significant difference in ${ }^{18} \mathrm{~F}-\mathrm{FDG}$ uptake by tumors defined as normoxic on the basis of ${ }^{60} \mathrm{Cu}$-ATSM uptake and those defined as hypoxic was noted. Thus, our results also support the notion that the prognostic information derived from ${ }^{60} \mathrm{Cu}$-ATSM PET cannot be derived from ${ }^{18} \mathrm{~F}-\mathrm{FDG}$ PET.

One of the limitations of ${ }^{60} \mathrm{Cu}$-ATSM for widespread clinical use is related to its short radioactive half-life $(0.40 \mathrm{~h})$. However, another radionuclide of copper, ${ }^{64} \mathrm{Cu}$, has a much longer half-life $(12.7 \mathrm{~h})$ and provides superior image quality in comparison with ${ }^{60} \mathrm{Cu}$. Several companies, such as MDS Nordion, ACOM, Trace Life Sciences, and IsoTrace, are now supplying ${ }^{64} \mathrm{Cu}$ for use in the labeling of radiopharmaceuticals, such as ${ }^{64} \mathrm{Cu}$-ATSM (40). With the increasing availability of ${ }^{64} \mathrm{Cu}$, it is likely that larger clinical trials with ${ }^{64} \mathrm{Cu}$-ATSM will be initiated in several regions of the world.

Pretherapy information on the oxygenation status of a tumor could play an important role in treatment selection. We have demonstrated that imaging with ${ }^{60} \mathrm{Cu}$-ATSM PET is a promising method for the assessment of tumor hypoxia and has the potential to be clinically useful in the care of patients with cancer. We confirmed our earlier results showing that the uptake of ${ }^{60} \mathrm{Cu}$-ATSM correlates well with patient survival for patients with cervical cancer. Although such information can be obtained with the oxygen electrode method, imaging offers several important advantages, including the ability to perform repeated, noninvasive assessments of hypoxia in the entire tumor regardless of the location of 
the tumor. This method can be used to identify patients for clinical trials of treatment strategies designed to overcome hypoxia.

\section{ACKNOWLEDGMENTS}

The authors greatly appreciate the technical support provided by Linda Becker, Jennifer Frye, and Helen Kaemmerer. We also acknowledge Tom F. Voller, Lucie Tang, Todd A. Perkins, Dr. Rajendra Singh, Sally W. Schwarz, and the cyclotron staff at Washington University School of Medicine for their valuable assistance in the production of ${ }^{60} \mathrm{Cu}$. This work was supported by NIH Grant CA81525 and DOE Grant DE-FG02-87ER60512.

\section{REFERENCES}

1. Brown JM. The hypoxic cell: a target for selective cancer therapy-eighteenth Bruce F. Cain Memorial Award lecture. Cancer Res. 1999;59:5863-5870.

2. Brown JM, Giaccia AJ. The unique physiology of solid tumors: opportunities (and problems) for cancer therapy. Cancer Res. 1998;58:1408-1416.

3. Hockel M, Knoop C, Schlenger K, et al. Intratumoral pO2 predicts survival in advanced cancer of the uterine cervix. Radiother Oncol. 1993;26:45-50.

4. Hockel M, Knoop C, Schlenger K, Vorndran B, Knapstein PG, Vaupel P. Intratumoral pO2 histography as predictive assay in advanced cancer of the uterine cervix. Adv Exp Med Biol. 1994;345:445-450.

5. Hockel M, Schlenger K, Aral B, Mitze M, Schaffer U, Vaupel P. Association between tumor hypoxia and malignant progression in advanced cancer of the uterine cervix. Cancer Res. 1996;56:4509-4515.

6. Hockel M, Schlenger K, Hockel S, Aral B, Schaffer U, Vaupel P. Tumor hypoxia in pelvic recurrences of cervical cancer. Int J Cancer. 1998;79:365-369.

7. Hockel M, Schlenger K, Knoop C, Vaupel P. Oxygenation of carcinomas of the uterine cervix: evaluation by computerized $\mathrm{O} 2$ tension measurements. Cancer Res. 1991;51:6098-6102.

8. Rofstad EK, Sundfor K, Lyng H, Trope CG. Hypoxia-induced treatment failure in advanced squamous cell carcinoma of the uterine cervix is primarily due to hypoxia-induced radiation resistance rather than hypoxia-induced metastasis. $\mathrm{Br} \mathrm{J}$ Cancer. 2000;83:354-359.

9. Pitson G, Fyles A, Milosevic M, Wylie J, Pintilie M, Hill R. Tumor size and oxygenation are independent predictors of nodal diseases in patients with cervix cancer. Int J Radiat Oncol Biol Phys. 2001;51:699-703.

10. Isa AY, Ward TH, West CM, Slevin NJ, Homer JJ. Hypoxia in head and neck cancer. Br J Radiol. 2006;79:791-798.

11. Vāvere AL, Lewis JS. Cu-ATSM: a radiopharmaceutical for the PET imaging of hypoxia. Dalton Trans. 2007;Nov 21:4893-4902.

12. Lewis JS, McCarthy DW, McCarthy TJ, Fujibayashi Y, Welch MJ. Evaluation of ${ }^{64} \mathrm{Cu}-$ ATSM in vitro and in vivo in a hypoxic tumor model. J Nucl Med. 1999;40:177-183.

13. Dehdashti F, Grigsby PW, Mintun MA, Lewis JS, Siegel BA, Welch MJ. Assessing tumor hypoxia in cervical cancer by positron emission tomography with $60 \mathrm{Cu}$-ATSM: relationship to therapeutic response-a preliminary report. Int J Radiat Oncol Biol Phys. 2003;55:1233-1238.

14. Grigsby PW. Modification of the radiation response of patients with carcinoma of the uterine cervix. Cancer Control. 1999;6:343-351.

15. Perez CA. Uterine cervix. In: Perez CA, Brady LW, eds. Principles and Practice of Radiation Oncology. 3rd ed. Philadelphia, PA: Lippincott-Raven; 1998:1733-1834.

16. McCarthy DW, Bass LA, Cutler PD, et al. High purity production and potential applications of copper-60 and copper-61. Nucl Med Biol. 1999;26:351-358.

17. Young H, Carnochan P, Zweit J, Babich J, Cherry S, Ott R. Evaluation of copper(II)-pyruvaldehyde bis (N-4-methylthiosemicarbazone) for tissue blood flow measurement using a trapped tracer model. Eur J Nucl Med. 1994;21:336-341.

18. Adam LE, Zaers J, Ostertag H, Trojan H, Bellemann ME, Brix G. Performance evaluation of the whole-body PET scanner ECAT EXAT HR + following the IEC standard. IEEE Trans Nucl Sci. 1997;44:1172-1179.
19. Dehdashti F, Mintun MA, Lewis JS, et al. In vivo assessment of tumor hypoxia in lung cancer with 60Cu-ATSM. Eur J Nucl Med Mol Imaging. 2003;30:844-850.

20. Vaupel P, Mayer A, Hockel M. Tumor hypoxia and malignant progression. Methods Enzymol. 2004;381:335-354.

21. Brizel DM, Scully SP, Harrelson JM, et al. Tumor oxygenation predicts for the likelihood of distant metastases in human soft tissue sarcoma. Cancer Res. 1996;56:941-943.

22. Nordsmark M, Bentzen SM, Rudat V, et al. Prognostic value of tumor oxygenation in 397 head and neck tumors after primary radiation therapy: an international multi-center study. Radiother Oncol. 2005;77:18-24.

23. Fyles A, Milosevic M, Hedley D, et al. Tumor hypoxia has independent predictor impact only in patients with node-negative cervix cancer. J Clin Oncol. 2002;20: 680-687.

24. Nordsmark M, Loncaster J, Aquino-Parsons C, et al. The prognostic value of pimonidazole and tumour $\mathrm{pO} 2$ in human cervix carcinomas after radiation therapy: a prospective international multi-center study. Radiother Oncol. 2006;80:123-131.

25. Padhani AR, Krohn KA, Lewis JS, Alber M. Imaging oxygenation of human tumours. Eur Radiol. 2007;17:861-872.

26. Eschmann SM, Paulsen F, Reimold M, et al. Prognostic impact of hypoxia imaging with ${ }^{18} \mathrm{~F}$-misonidazole PET in non-small cell lung cancer and head and neck cancer before radiotherapy. J Nucl Med. 2005;46:253-260.

27. Rischin D, Hicks RJ, Fisher R, et al. Prognostic significance of $\left[{ }^{18} \mathrm{~F}\right]$-misonidazole positron emission tomography-detected tumor hypoxia in patients with advanced head and neck cancer randomly assigned to chemoradiation with or without tirapazamine: a substudy of Trans-Tasman Radiation Oncology Group Study 98.02. J Clin Oncol. 2006;24:2098-2104.

28. Dietz DW, Dehdashti F, Grigsby PW, et al. Tumor hypoxia detected by positron emission tomography with ${ }^{60} \mathrm{Cu}$-ATSM as a predictor of response and survival in patients undergoing neoadjuvant chemoradiotherapy for rectal carcinoma: a pilot study. Dis Colon Rectum. In press.

29. Vansteenkiste JF, Stroobants SG, Dupont PJ, et al. Prognostic importance of the standardized uptake value on (18)F-fluoro-2-deoxy-glucose-positron emission tomography scan in non-small-cell lung cancer: an analysis of 125 cases. Leuven Lung Cancer Group. J Clin Oncol. 1999;17:3201-3206.

30. Oshida M, Uno K, Suzuki M, et al. Predicting the prognoses of breast carcinoma patients with positron emission tomography using 2-deoxy-2-fluoro[ $\left.{ }^{18} \mathrm{~F}\right]-\mathrm{D}$ glucose. Cancer. 1998;82:2227-2234.

31. Kallinowski F, Brownell AL, Vaupel P, Brownell GL. Combined tissue oxygen tension measurement and positron emission tomography studies on glucose utilization in oncogene-transformed cell line tumour xenografts in nude mice. $\mathrm{Br} \mathrm{J}$ Radiol. 1991;64:350-359.

32. Clavo AC, Brown RS, Wahl RL. Fluorodeoxyglucose uptake in human cancer cell lines is increased by hypoxia. J Nucl Med. 1995;36:1625-1632.

33. Minn H, Clavo AC, Wahl RL. Influence of hypoxia on tracer accumulation in squamous-cell carcinoma: in vitro evaluation for PET imaging. Nucl Med Biol. 1996;23:941-946.

34. Pugachev A, Ruan S, Carlin S, et al. Dependence of FDG uptake on tumor microenvironment. Int J Radiat Oncol Biol Phys. 2005;62:545-553.

35. Rajendran JG, Mankoff DA, O'Sullivan F, et al. Hypoxia and glucose metabolism in malignant tumors: evaluation by $\left[{ }^{18} \mathrm{~F}\right]$ fluoromisonidazole and $\left[{ }^{18} \mathrm{~F}\right]$ fluorodeoxyglucose positron emission tomography imaging. Clin Cancer Res. 2004;10:2245-2252.

36. Zhao S, Kuge Y, Mochizuki T, et al. Biologic correlates of intratumoral heterogeneity in ${ }^{18} \mathrm{~F}-\mathrm{FDG}$ distribution with regional expression of glucose transporters and hexokinase-II in experimental tumor. J Nucl Med. 2005;46:675-682.

37. Tanaka T, Furukawa T, Fujieda S, Kasamatsu S, Yonekura Y, Fujibayashi Y. Double-tracer autoradiography with $\mathrm{Cu}-\mathrm{ATSM} / \mathrm{FDG}$ and immunohistochemical interpretation in four different mouse implanted tumor models. Nucl Med Biol. 2006;33:743-750.

38. Thorwarth D, Eschmann SM, Holzner F, Paulsen F, Alber M. Combined uptake of $\left[{ }^{18} \mathrm{~F}\right] \mathrm{FDG}$ and $\left[{ }^{18} \mathrm{~F}\right] \mathrm{FMISO}$ correlates with radiation therapy outcome in headand-neck cancer patients. Radiother Oncol. 2006;80:151-156.

39. Cherk MH, Foo SS, Poon AM, et al. Lack of correlation of hypoxic cell fraction and angiogenesis with glucose metabolic rate in non-small cell lung cancer assessed by ${ }^{18}$ F-fluoromisonidazole and ${ }^{18}$ F-FDG PET. J Nucl Med. 2006;47:1921-1926.

40. Lewis JS, Welch MJ, Tang L. Workshop on the production, application and clinical translation of "non-standard" PET nuclides: a meeting report. $Q \mathrm{~J} \mathrm{Nucl}$ Med Mol Imaging. November 28, 2007 [Epub ahead of print]. 